\title{
Primary Healthcare Strengthening through Distance Education for Health Professionals
}

\author{
Karunathilake, I.M. ${ }^{1}$, Bandara, J. ${ }^{2}$, Attygalle, $D .^{2}$, Gunawardena, C.N. ${ }^{3}$, Egodage, T. , \\ Chandrasena, $U^{1}$
}

\begin{abstract}
Introduction: Primary Health Care is proven to be a highly effective and efficient way to address poor health and well-being. Despite its achievements Sri Lanka's PHC System, specialized for preventive and curative actions, is increasingly under pressure due to chronic and non-communicable diseases. Developing the broad range of skills necessary for medical practice in the existing PHC settings should be achieved through continuous professional development. A distant learning programme through eLearning is a model solution to expand the existing boundaries for CPD.

Methods: Sri Lanka Medical Association, Ministry of Health, Primary Healthcare System Strengthening Project and World Bank have collaboratively worked as key stakeholders to develop and implement a course for capacity building among the medical professionals. The first phase of the course was developed with 6 priority modules consisting of Ministry of Health approved content conjoined with digital material. Participants were provided with additional resources. The course was evaluated by assessing user involvement and users' perception towards the course. The course reflected a positive involvement for majority of modules and a generally positive feedback despite the response rate being considerably low.
\end{abstract}

Discussion: Vulnerabilities in the system could be identified including shortcomings of the system, instructors and learning material, and administration issues. Including diverse course materials, provision of incentives for participation, training resource persons and other recommendations may allow better distance learning experience with desired outcomes.

Conclusion: Distance learning through an eLearning platform is an ideal way to address CPD in PHC through timely modules, appropriate learning material, user friendly interface, efficient evaluation methods, and an effective system improving procedure. This course has enabled medical professional to develop their insights in PHC, however the shortcomings should not be neglected.

Keywords: Primary Health Care, Continuous Professional Development

\begin{abstract}
Introduction
Primary Health Care covers majority of a person's health needs throughout their life including prevention, treatment, rehabilitation and palliative care, as substantiated by the WHO. By providing care in the community as well as care through the community, a well systematized PHC scheme would addresses not only individual and family health needs, but
\end{abstract}

\footnotetext{
${ }^{1}$ Sri Lanka Medical Association

${ }^{2}$ World Bank Country Office, Sri Lanka

${ }^{3}$ University of New Mexico

Corresponding Author: Professor Indika Karunathilake, Department of Medical Education, Faculty of Medicine, University of Colombo, Sri Lanka.
}

Email: karunathilake@hotmail.com

DOI: http://doi.org/10.4038/seajme.v14i2.281 also the broader issue of public health and the needs of defined populations. While undertaking the mission of attaining Sustainable Development Goals (SGD) by 2030 , Primary health care has proven to be a highly effective and efficient way to address the main causes and risks of poor health and wellbeing today, besides handling the emerging challenges that threaten health and well-being tomorrow, thus contributing to the fulfilment of SGDs beyond the health goal (SGD3).

The PHC system in Sri Lanka, available free island-wide through a government health system consists of two delivery arms specialized for preventive and curative actions. The provision of primary healthcare facilities focusing on maternal and childcare and the

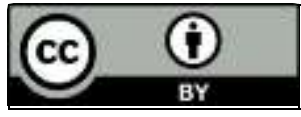

(C) SEAJME. This is an Open Access article distributed under the terms of the Creative Commons Attribution License (http://creativecommons.org/licenses/by/4.0/), which permits unrestricted use, distribution, and reproduction in any medium, provided the original author and source are credited 
curative services conducted by divisional hospitals and primary medical care units is noteworthy considering the successes in universal immunization coverage, reduction of maternal mortality and infant mortality, control of diarrhoeal diseases, elimination of malaria, filariasis and neonatal tetanus, and low prevalence of HIV (Perera and Perera, 2017). However the system is increasingly under pressure markedly due to the growing number of chronic and non-communicable diseases including cardiovascular diseases (CVD) such as ischemic heart disease and stroke, cancers, diabetes, and respiratory conditions such as asthma, and the increasing elderly care needs (Ministry of Health, 2017).

The country's newly aroused consensus among the general public concerning the underutilisation of primary care facilities is further abetted by the lack of confidence in PHC services among the population, due to several factors including poor infrastructure and negative attitudes of staff. This situation generates overcrowding at secondary and tertiary health care levels, including teaching hospitals, highlighting the requirement for capacity building among the medical professionals.

Despite the above concerns, the main target of "Increasing the utilization and quality of PHC services, with an emphasis on the detection and management of NCDs of high-risk population groups, in selected areas of the country" is yet to be achieved within the health system. While emphasizing this objective, updating medical professionals on clinical knowledge and, developing and improving the broad range of skills necessary for medical practice in the existing primary care settings shouldn't be neglected. Precisely, Continuous Professional Development (CPD) and Continuing Medical Education (CME) in Primary Healthcare should be empowered island wide, aiming to provide better quality health care by keeping the physicians' practice up to-date.

In Sri Lanka, regardless of the fact that practices and policies for CPD are still evolving whilst the CPD programme remains an entirely voluntary programme, a number of organizations provide CPD opportunities for medical professionals. Whereas most of the primary healthcare improving CPD and CME activities are limited to urban areas such as Colombo or Kandy, medical officers and other health professionals in suburban or rural areas have considerably fewer access to such programmes. Difficulties such as finances, time constraints, job demand and work-life balance faced by the medical professionals only worsen the situation. A distance learning programme that can provide CPD and CME is an ideal way to address these problems providing opportunities for enhanced participation and convenience, in the current context.

Distance learning through an eLearning platform has become part of the mainstream in medical education, and has expanded its branches to countless regions, providing distinct areas of activity including E-learning, Eteaching and E-assessment (Harden, 2005). Although there are a great many tools used in the delivery of e-learning, the most common approach is to use an integrated suite of tools and services, typically called a Learning Management System (LMS), Course Management System (CMS) or a Virtual Learning Environment (VLE). Even though the temptation for distance learning to merely broadcast material to large numbers of learners should be resisted, once the nature of online distance learning and the needs of the distance learners are understood, distance learning allows for a learning experience as rich as any campus-based experience.

\section{Background}

The shift of disease epidemiology from communicable diseases to noncommunicable diseases has alarmed Sri Lanka and has led to the reorganization of the primary healthcare sector of the country. Accordingly, since year 2018, the Ministry of Health, Sri Lanka has put its effort to implement the primary healthcare reorganization programme for the country, which drives for people centered care, instead of the traditional system of episodic care.

In this regard, capacity building among the Primary Healthcare staff is identified as a priority requirement. Also, it has become a mandatory requirement for the achievement of the targets of the Primary Healthcare System Strengthening project; one of the key initiatives of the Ministry of Health facilitated PHC reorganization activities at Primary Medical Care Institutes.

Introduction of eLearning for primary care staff is one of the key solutions identified by the Ministry of Health in order to address the above capacity building need without disturbing the routine activities in work station. Accordingly, in 2018 the Ministry of Health launched a digital health platform for e-learning and started ground work to initiate distance learning courses for Medical Officers in Primary Care using this platform. Sri Lanka Medical 
Association, Ministry of Health's Primary Healthcare System Strengthening Project and the World Bank have collaboratively worked as key stakeholders to develop and implement the distance learning program.

\section{Methodology Course Development}

The distance learning programme in regard to the Primary Healthcare System Strengthening Project was developed with the participation of all stakeholder parties, whereas course development and implementation was administered by a steering committee, appointed by the Secretary, Ministry of Health. Additional Secretary (Medical Services) of the Ministry of Health held the chairmanship of this committee. Development of the storyline and the digital content were executed and consulted separately.

Following a consultative session with Sri Lanka Medical Association and College of Family Physicians to design an online program in primary care, 12 modules were identified with timely and judicious importance, with specialists for each module. In the process of gradually developing the course, 6 priority modules were identified for the first phase of course development, as follows:

1) Role of the Medical Officer in the Primary Medical Care Institution (PMCl)

2) Screening and Management of NonCommunicable Diseases at $\mathrm{PMCl}$

3) Diagnosing and Managing Tuberculosis

4) Cardiovascular Diseases
5) Diagnosis and Management of Diabetes Mellitus in PMCl

6) Role of the Primary Care doctor in the identification and management of Dengue

The selected 6 modules were then directed to subject matter specialists for development of technical content and storyboard. The relevant directories of the Ministry of Health approved the storyboard for further proceedings. This was followed by the procurement of an agency to design the modules in the selected Learning Management System (LMS). With the guidance of academic experts on the subject, the digital content for the 6 priority modules was developed. After getting approved by the Ministry of Health, the digital content for the six priority modules was run on the platform.

\section{Course Implementation}

Fifty medical officers representing verifiable hospitals of the PSSP were selected for the commencement of the programme and other medical officers were gradually enrolled, increasing the total number to 105 . The program was opened to participants with the introductory module on Primary care and subsequently the other course modules were opened, including Non communicable Diseases - Screening and Management, Tuberculosis, Cardiovascular Diseases, Diabetes and Dengue.

Responsibilities of course implementation were delegated among relevant stakeholder parties as follows (Table 1)

Table 1: Responsibilities among the stakeholders for Course Implementation

\begin{tabular}{|c|c|}
\hline Activity & Responsibility \\
\hline $\begin{array}{l}\text { Administrative procedures to enroll Medical Officers in } \\
\text { the course }\end{array}$ & $\begin{array}{l}\text { Deputy Director General of Education and } \\
\text { Research }-\mathrm{MOH}\end{array}$ \\
\hline Creation of user logins and facilitation of user access & Agency and Health Information unit \\
\hline $\begin{array}{l}\text { Attending to user login issues among users and other } \\
\text { technical problems }\end{array}$ & Agency and PSSP, WB Consultant \\
\hline Conduct virtual sessions relevant to each module & Module coordinators and SLMA \\
\hline $\begin{array}{l}\text { Mentoring support to participants in the } \\
\text { implementation of each module }\end{array}$ & Module coordinators \\
\hline $\begin{array}{l}\text { Continuous follow and feedback with participants } \\
\text { during course of the programme }\end{array}$ & SLMA and PMU \\
\hline $\begin{array}{l}\text { Assessment of the programme through Focus group } \\
\text { (Virtual) }\end{array}$ & $\mathrm{PMU} / \mathrm{WB}$ \\
\hline
\end{tabular}


In addition to the modules, the participants were provided with access to several CPD resources provided by SLMA including the CPD platform, online Library, and the SLMA Annual conference (100 participants were sponsored by the World Bank). Access to SLMA Webinars, with virtual classroom experience, was also provided for the participants.

The initially recognized user login issues and other technical problems were identified by the agency and remedied. Three virtual sessions were conducted for the modules of NCD, CVD and Diabetes whereas short assessment through focus group discussion (FGD) was conducted and findings were disseminated to $\mathrm{PMU} / \mathrm{MOH}$, for further consultations. Regular contacts with the participants have been maintained throughout the period by PSSP. The participants were informed of the start of each new module via electronic mail, voice calls and short message services (SMS). Participants were also reminded to join the ongoing modules using these same methods.

The online portal is now fully functional with six priority modules and 105 participants.
Technical bugs in each module were rectified by the agency procured, with the consultation of the Health Information Unit of the $\mathrm{MOH}$.

\section{Course Evaluation}

The evaluation of the course was executed by assessing participants' involvement and perception towards the course. Participant involvement of the course was assessed through the number of active participants for each module, 'completed' and 'in progress' participants respectively, whereas participants' perception towards the course was assessed through a focus group interview that was analyzed using qualitative content analysis.

\section{User Involvement}

All the student participants had access to all six modules, and a majority of participants have actively participated in the modules, either "completed" or "In progress". However, some have not started certain modules, albeit the continuous reminders, showing no interest in the learning material

Table 2: Active participants for each module

\begin{tabular}{lc}
\hline \multicolumn{1}{c}{ Module } & Active users \\
& (Max-105) \\
\hline Role of the Medical Officer in the Primary Medical Care Institution (PMCl) & 64 \\
\hline Screening and Management of Non-Communicable Diseases at PMCI & 85 \\
\hline Diagnosing and Managing Tuberculosis & 59 \\
\hline Cardiovascular Diseases & 86 \\
\hline Diagnosis and Management of Diabetes Mellitus in PMCl & 93 \\
\hline Role of the Primary Care doctor in the identification and management of Dengue
\end{tabular}

When considering the six initiated modules the highest active user participation could be seen for the module "Diagnosis and Management of Diabetes Mellitus in PMCII" (88.6\%), followed by the module "Cardiovascular Diseases"
$(81.9 \%)$, while the module "Role of the Primary Care doctor in the identification and management of Dengue" was encountered with the least preference $(10.5 \%)$. (Figure 1 below) 


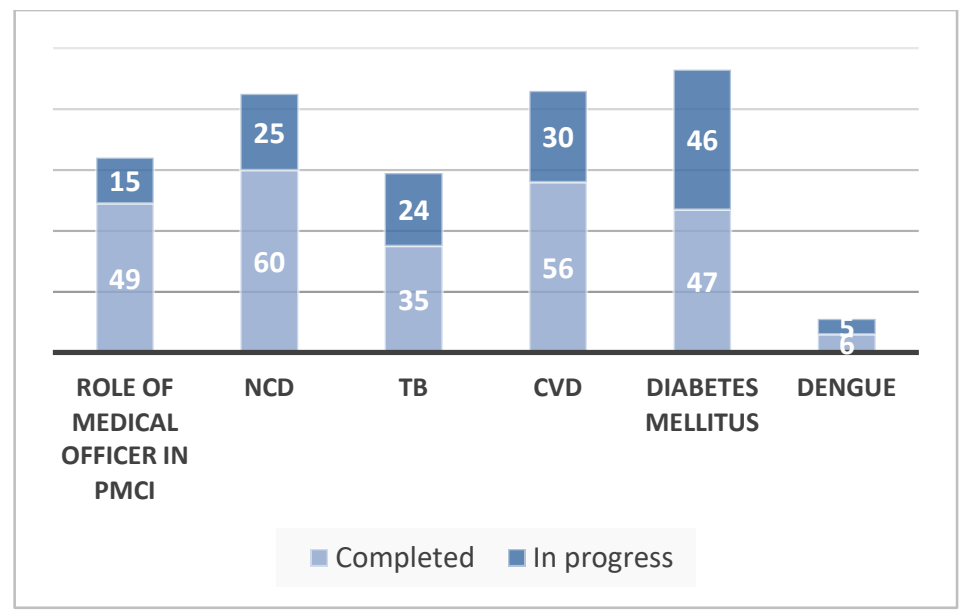

Figure 1: Completed and In-progress participants

Even though the module "Role of the Primary Care doctor in the identification and management of Dengue" has been initiated before the module on Diabetes Mellitus, the participation rate has been considerably low. This may be due to the user preferences, or due to drawbacks on course material and layout.

\section{User Feedback}

User feedback of the course was evaluated twice, eight and ten months after the course initiation respectively, through a qualitative assessment.

During the first course feedback the usefulness of the online learning experience for participants those who own family practice was estimated, on a 10 point scale ( $1=$ Not useful at all to $10=$ Very useful). Average rating was from
8.6, from 16 participants $(\mathrm{N}=16)$. A large majority $(\mathrm{N}-14)$ selected values between $8-10$, with 4 participants giving full marks. This indicates a very positive rating for the usefulness of the online learning experience for participants who own family practice.

In the second course evaluation, user's feedback was assessed through a google form emailed to the participants, requesting their response on the course contentment, course flow and format, course accessibility, altitudes towards the course, and the benefits accomplished from the course. Albeit the number of participants who submitted their responses being 13 ( $\mathrm{N}=13$ and Response rate - $12.4 \%$ ), the overall feedback was positive, indicating the practicality and usefulness of the course (Figure 2).

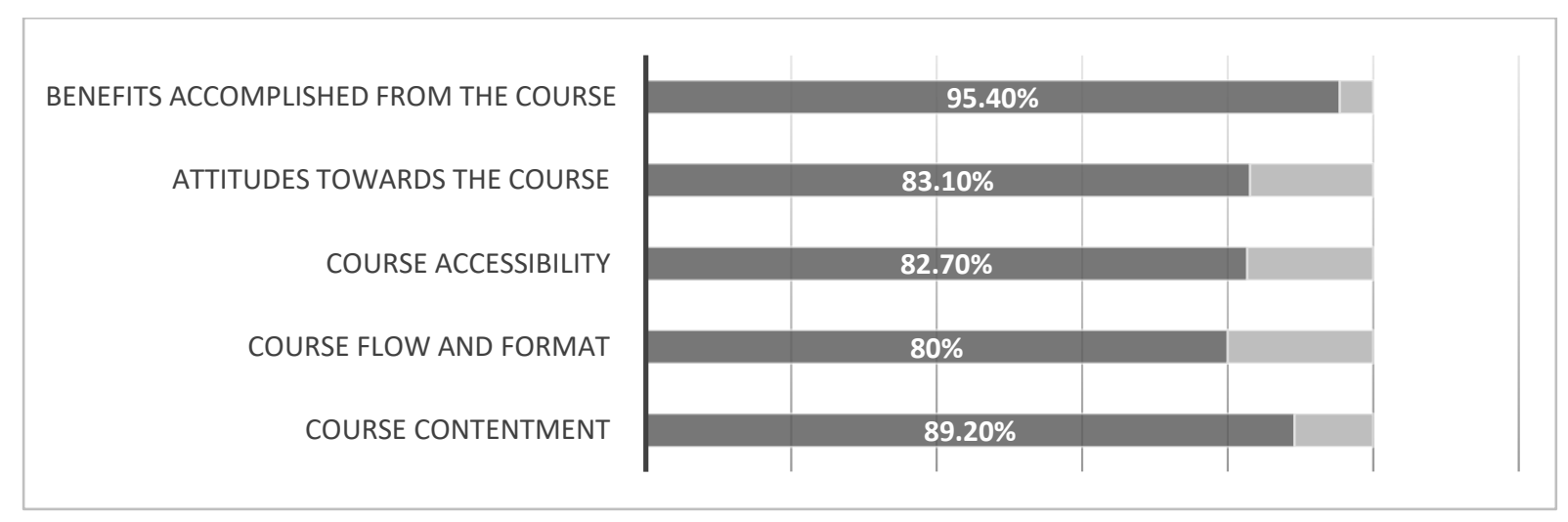

Figure 2: Positive responses towards the course, for each competency (Evaluation 2)

\section{Discussion}

General distance education literature suggest that a distance learning setting may include the lack of support due to physical absence of teacher, lack of student to student communication, inability to control pace and progress of the course, and the challenges in maximum use of technology (Bilgic and Tuzun, 2020; Rana and Lal, 2014). In this platform, the video material where the instructor would explain the module overview and the outcomes 
can be identified as an attempt to overcome the lack of instructor support and student to student interaction. Implementing self-study practices for CPD was important in order to encourage them to further research topics they are interested in. The reading list, resources and references available in each module benefit this concept. Therefore participants' attentiveness matters to the success of the overall project. The participants' perception towards CPD through distance learning may be partly attributed to the high levels of professional education, high interest in professional development, and their experience in online learning and using internet.

\section{Challenges}

This distance learning project, as with most ventures, was not without its limitations and challenges. Both vulnerabilities in the system and other resources could be identified. Even though the programme was designed especially for distance learning, the internet access issues in remote locations in the country, restrained its functionality. Course activation was difficult since the user had to obtain login and password details from course administrators. Course material for majority of courses was in video format which was difficult to access especially in low-bandwidth areas, some learning material in the course had technical issues, and the sustainability of the platform was not ensured. The limited instructor/module coordinator participation in the modules was noticeable, and course deadlines were not strictly adhered to, resulting in unsatisfactory motivation for the learners.

During the focus group interview, participants reported that the proprietary eLearning platform was not user friendly. Inability to resume course/assignments where one leaves off, and revisiting restrictions for completed modules were found to be drawbacks of the system. System generated data does not discriminate between different types of users enrolled in the LMS such as participants, tutors, administrators, technical staff, ministry officials, project staff, SLMA and College officials, which was a major inadequacy of the system. This problem provides an erroneously low number of course completions, thus misinterpretations occur when the statistics are obtained straight from the platform's website. Difficulty to edit and improve the course material was encountered by course authors as the service provider would allow only a limited number of editing, reducing flexibility for further improvement.

\section{Recommendations}

We make three recommendations for improving the distance learning experience for participants. The first is to provide incentives for participants to engage in CPD by providing release time to complete the modules. The second is to train resource persons to facilitate online learning both asynchronously and synchronously, for example, on how to establish social presence, engage the learner, interact, and build community at a distance. The third recommendation is to improve the technical platform issues encountered by participants, such as providing a selfenrollment option when a password is lost, enabling ability to resume course/assignments where one left off, and including diverse options to access course material in low bandwidth areas, such as providing access to PPTs and PDFs when video is used.

\section{Conclusion}

Distance learning through an eLearning platform, is an ideal way to address CPD and strengthen primary health care. A platform designed for this purpose should consist of timely modules, appropriate learning material, user friendly interface, efficient evaluation methods, and an effective system improving procedure. This distance learning programme has benefitted medical professionals to develop their insights in primary care, with a comprehensive initial programme consisting of course development, course implementation and course evaluation. The active participants' perception towards the overall course has been positive. However, it is important to address the shortcomings of the system, instructor training and learning management system administration issues in order to make better provision of CPD in primary care.

\section{Conflicts of Interest}

The authors declare no conflict of interest.

\section{References}

Bilgic, H.G. and Tuzun, H. (2020). Issues and Challenges with Web-Based Distance Education Programs in Turkish Higher Education Institutes. Turkish Online Journal of Distance Education, 21(1), pp.143-164.

da.health.gov.Ik. SLMA Facilitated by World Bank Global Fund. [online] Available at: https://da.health.gov.lk [Accessed 21 Oct. 2020].

Ellaway, R. and Masters, K.(2008) AMEE Guide 32: e-Learning in medical education Part 1: Learning, teaching and assessment. Medical teacher, 30(5), pp.455-473. 
Harden, R.M. (2005). A new vision for distance learning and continuing medical education. Journal of Continuing Education in the Health Professions, 25(1), pp.43-51.

Kulatunga, G.G., Marasinghe, R.B., Karunathilake, I.M. and Dissanayake, V.H. (2013) Development and implementation of a web-based continuing professional development (CPD) programme on medical genetics. Journal of telemedicine and telecare, 19(7), pp.388-392.

Perera, A. and Perera, H.S.R. (2017). PRIMARY HEALTH CARE SYSTEMS (PRIMASYS)-Case study from Sri Lanka.
Rana, H. and Lal, M. (2014). E-learning: Issues and challenges. International Journal of Computer Applications, 97(5).

Reorganising Primary Health Care in Sri Lanka PRESERVING OUR PROGRESS, PREPARING OUR FUTURE Ministry of Health, Nutrition and Indigenous Medicine Sri Lanka. (2017). [online] Available at: http://www.health.gov.lk/moh_final/english/ public/elfinder/files/publications/2018/Reorg PrimaryHealthCare.pdf.

World Health Organization: WHO (2019). Primary health care. [online] Who.int. Available at: https://www.who.int/healthtopics/primary-health-care\#tab=tab_ 